\title{
Towards a More Nuance Understanding of White Teachers of English Learners: Increasing Capacity and Capabilities
}

\author{
Jenna Min Shim \\ School of Teacher Education, University of Wyoming, USA
}

\begin{abstract}
Predicated on the idea that race, racialization, and racism are major factors that shape language teaching and learning, this paper draws on the second wave White teacher identity studies to argue for a more nuanced understandings on White monolingual teachers' racial identities by exploring their perspectives on English learners' (ELs') learning experiences by asking the following research questions: (1) From the EL teachers' perspectives, what contribute to EL's struggles in school? (2) What effects do the EL teachers' perspective have on ELs' school experiences? (3) Are there any consistencies or inconsistencies among the participants' perspectives and what do they mean? The findings report that tensions and contradictions arising from inconsistencies across the participants' perspectives as well as within each teacher's perspective reflect co-existence of race evasive and race conscious identities that in turn can serve as an important locus to transform their perspectives toward more equitable pedagogical practices for ELs.
\end{abstract}

Index Terms - race, race-evasive approach, race-visible approach, English learners, second wave white teacher identity

\section{INTRODUCTION}

This paper draws on the second wave White teacher identity studies to argue for a more nuanced understanding on White monolingual teachers' racial identities by exploring their perspectives on English learners' (ELs') learning experiences. In the present time, the teaching force remains predominantly monolingual and White in the US as well as in other countries (Bergh, Denessen, Hornsta, Voeten, \& Holland, 2010; Kang \& Veitch, 2017). Research also establishes that the number of teachers in public schools who have adequate training to work with ELs are limited and teachers struggle meeting the needs of ELs (Zumwalt \& Craig, 2005). Research further demonstrates that many White monolingual teachers lack disposition necessary to work productively with ELs in many countries. (Zhang \& Pelttari, 2013).

Despite the fact that there is a clear and prominent racial gap between the students who are ELs and their teachers, and the field of teaching English to speakers of other language has not sufficiently addressed the idea of race and related concepts (Kubota \& Lin, 2006). However, existing research studies demonstrate that racialization is inevitably salient in English language teaching (Kumaravadivelu, 2003; Pennycook, 2001), and the identities of EL teachers are multilayered and cannot be examined without an eye toward race and language because the idea of race and racialization are factors that shape social and cultural dimensions of language teaching and learning (Motha, 2006; Taylor, 2006). Researchers who have explored the issues of teachers' race in English language teaching have argued that many White monolingual teachers of ELs embody Eurocentric values, unknowingly perpetuating the status quo and inequality already in place for ELs (Doorn \& Schumm, 2013; Flores \& Rosa, 2015; Motha; 2006; Taylor, 2006). Some have demonstrated the ways in which colorblind perspectives stemming from White privilege obscure issues of power consequently securing racial and linguistic hierarches (Lee \& Simon-Maeda, 2006); thus, many also argued that there is an urgent need to support White teachers to disrupt their assumptions that can impair ELs and their academic achievement (Assaf, Garza, \& Batt, 2010; Walker-Dalhouse, Sanders, \& Dalhouse, 2009).

Similar research findings are also well known in the field of teacher education in regards to race. Several teacher education researchers who explored White teachers' racial identity reported the way that White teachers are color blind individuals who are in need of more self-reflexivity and intervention (Gay \& Kirkland, 2003; McIntyre, 1997, 2002; Picower, 2009). One common coomitment that these research studies share is the commitment to more equitable pedagogical practices especially for students from racially diverse backgrounds. A predilection carried by these studies is that White teachers' acknowledging their racial bias and White privilege will lead to more just pedagogical practice (Lensmire et al., 2013).

Adopting and complexifying the previous critical Whiteness studies, second-wave White teacher identity scholars contend that, to move the discussion of race and racism forward in ways that leads to action that would ultimately advance more equal educational opportunities for students of color (Shim, 2018), we need more nuanced, nonessentializing, and complex understandings of White teachers' identity without reducing it solely to raceevasiveness or color-blindness (Jupp, Berry, \& Lensmire, 2016; Jupp \& Lensmire, 2016; Jupp \& Slattery, 2010; 
Lensmire, 2011, 2014). Recognizing that not all ELs are students of color and also recognizing there is a near avoidance of race in the language teaching and learning field because it is uncomfortable work (Kubota, 2002; Kubota \& Lin, 2006), because majority of ELs in the US and other places in the world are from racially diverse backgrounds while their teachers are predominantly White, this study echoes the commitment of the second-wave White teacher identity research. This study is committed to the understanding that the idea of race, racialization and racism are inescapable topics that arise in teaching English worldwide and thus are necessary topics to explore in the field of English teaching (Kubota \& Lin, 2006; Motha, 2006; Taylor, 2006).

To this end, closer attention is given to complexity five English as a second language (ESL) teachers' understanding of their ELs learning experience by asking the following research questions: (1) From the EL teachers' perspectives, what contribute to EL's struggles in school? (2) What are the effects these EL teachers' perspective on ELs' school experiences? (3) Are there any consistencies or inconsistencies among these teachers' perspectives and what do they mean?

One of the uniqueness of the study lies in the fact that the study focuses on a rural context in a mid- western US state. The dramatic increase in linguistic diversity is no longer pertains only to large metropolitan areas, and the growth has been much more prominent in less populated rural states. O'Neal, Ringler, and Rodriguez (2008) reported that "ELL students and their families tend to settle in geographical locations that are rural" (p. 6). Reed (2010) similarly stated that rural areas are experiencing a visible increase in linguistic and racial diversity in their student populations; therefore, schools in rural states are facing educational challenges in meeting the needs of diverse student populations, including ELs (Shim,2014).

One of the major factors that influence ELs' school experience is the beliefs of their teachers (Shim, 2014). Peregoy and Boyle (1997) showed that the beliefs and attitudes of teachers can affect what ELs learn and do not learn in their classrooms. Other researchers also noted that teachers' attitudes towards ELs shape how they interact with their ELs as well as their pedagogical decisions which ultimately impact ELs' academic achievement; and most of these studies have focused on how even well-intended teachers can hinder ELs' academic and social achievement if they have unexamined negative beliefs about ELs (Macnab \& Payne, 2003; Rueda \& Garcia, 1994; Pettit, 2011). Extending these arguments, this paper explores EL teachers' perspectives on the factors that contribute to ELs' academic challenges. The reason for this investigation is not to highlight the challenges. Rather, because ELs do face more linguistic limitation that can contribute to their academic challenges when compared to their native speaker of English counterparts, understanding the teachers' perspectives may provide a ground to reflect on what they can do to better support ELs' academic success. Following the commitment of the second-wave White teacher identity scholars, this study attends to the forces of historical and social racial inequality that speaks through the individual White teachers' perspectives but at the same time, the study is committed to understanding the participating teachers' perspectives as a complex, multidimensional and social-historical construction. The assumption implicit in this study is that these teachers' perspectives influence what they see as a productive pedagogy for ELs.

Drawing upon second-wave White teacher identity literature, the following section begins with a discussion of the conceptual framework that informs this study followed by a brief autobiographical sketch. Then in next section, the methodology is outlined proceeded by the findings and discussion sections. The final section offers the study conclusion and implication toward the implications of understanding White monolingual teachers' beliefs in more nuanced, complex and non-essentialized ways and what that means for more equitable educational practices for ELLs.

\section{CONCEPTUAL FRAMEWORKS}

\section{Second-wave White Teacher Identity Studies}

Extending the first-wave Whiteness and White privilege literature in which White teacher identity is presented as deficient and race-evasive (McIntyre, 1997, 2002; Sleeter,1993, 2002), Jupp and Slattery (2010) contended that the second-wave scholarship of White teacher identities must emphasize race-conscious identifications and "articulate identifications as process of self narrativization rather than essentializing identity state" (p. 455). According to Jupp, Berry, and Slattery (2016), existing understandings of White teacher identity focus on White teachers' insistence on erasing or evading group identities especially signifying historical oppression like race and instead emphasize individuals (race-evasive). Jupp et al. (2016) called for a shift from focusing essentialized White teacher identity solely based on race evasiveness to White teachers' identification creativity in Which White teachers' becoming is highlighted. For these authors, how White teachers are traditionally seen as deficient and color blind individuals in need of an intervention is counterproductive in moving the conversation on race and racism forward. Moreover, Jupp and Lensmire (2016) questioned and problematized the interventionist approach where researchers and teacher educators hold deficit views of White teachers as a homogeneous group who are unaware of the effects of race and racism. Relatedly, Lowenstein (2009) challenged essentialzed portrayal of White teachers and contended that, if teacher educators want teachers to view K-12 students who bring resources to their classrooms, "there is a need for a parallel conception of teacher candidates as active learners who bring resources to multicultural teacher education classrooms" (p. 163).

Relatedly, to allow the possibility of change and promote more equitable pedagogical practices, the second-wave White teacher identity scholars underscore the necessity of respecting teachers as authors of their own stories and regarding those teachers as learners who bring funds of knowledge and complex histories to the race related discussion 
(Lowenstein, 2009). The second-wave White teacher identity scholars argue that the authors of previous White teacher identity studies seldom take into account the social context and relations within which White teachers are performing their racial identities. To this end, attending to social context and relations within which White teachers working with ELs are making sense of their students' learning experiences is the main purpose of this study. More specifically, the aim of this study is to honor the participating teachers as the authors of their own sense-making within their lived experiences while also pay close attention to the social context within which participants take up their racial identity while discussing their perspectives. The study also responds to Lensmire's (2014) call for researchers to "describe and theorize White identity and Whiteness in ways that avoid essentializing them, but that at the same time never lose sight of White privilege and a larger White supremacist context" (p. 3) which is consistent with the commitment in the field of English language teaching and learning to not essentialize ELs' racial identities. This study is grounded on the idea that "critical work on race does not only study its real manifestations ... it must critically understand how people imagine race in their daily lives (Leonardo, 2005, p. 404). Again, recognizing that not all ELs are racially diverse students, because the majority of ELs in the US and many other places in the world are students of color whereas the majority of teachers who teach them are White, the second-wave White teacher identity scholarship provides a useful frame of reference to investigate ways to increase capacities and capabilities of White teachers in supporting ELs' academic success.

\section{METHODS}

\section{Setting}

This study took its place in a small town in a mid-western US state. This English only state has population of about 9,300 residents, and it is a primarily rural ranching community. The state penitentiary is located in this town, and this town is also home of two coal mine factories which provide many employment opportunities. Hence, the town's population has become increasingly diverse which also led to the influx of ELs being doubled in public schools in this town since 1990s.

There are two elementary schools, one middle school, and one high school in this town. A pull-out program for ELs whereby, during each school day, the ELs are taught English as a second language (ESL) during one to two hours designated hours and the rest of their day are the ELs are in mainstream classrooms. Currently, $26.6 \%$ of the total student population in this town is Hispanic, and Asians and Native Americans account for 4.1\% (Shim \& Shur, 2018). $11.8 \%$ of the total student population qualifies for ESL services, and more than $15 \%$ of the total student population lives in a home where one or both parents speak a language other than English as their first language (Wyoming Department of Education, 2017).

\section{Participants}

Two female elementary school ESL teachers, one female middle school ESL teacher, and a male and a female high school ESL teachers participated in this study. Each teacher's teaching experiences range from 3 to 8 years, and they all volunteered to participate in this study. All participants self-identified themselves as White Americans, aged 24 to 45 , and they do not speak any other language other than English. All participating teaching have completed their ESL certifications. The following is a table of the participants' demographic data. All names are pseudonyms (Shim, 2014).

TABLE 1.

PARTICIPANTS' DEMOGRAPHIC DATA

\begin{tabular}{|l|l|l|l|l|l|}
\hline Name & School & Race & Language & Yrs. Of ESL Teaching & Age \\
\hline Linda & Elementary & White & English & 6 & 38 \\
\hline Mary & Elementary & White & English & 3 & 24 \\
\hline Nancy & Middle & White & English & 8 & 45 \\
\hline Karen & High & White & English & 6 & 35 \\
\hline David & High & White & English & 4 & 32 \\
\hline
\end{tabular}

\section{Data Sources}

The findings reported in this study are based on 10 semi-structured individual interviews with the participating teachers. While not all interviews are directly quoted in this study, each participant engaged in two interviews with the researcher, and each interview lasted approximately 1-1.5 hours. Across the six months period all interviews were conducted, the aim of interviews was to elicit responses that would point to the main research question: From these EL teachers' perspectives, what contribute to EL's struggles in school? All interviews were recorded, and the researcher took careful and detailed notes. The recorded interviews were later transcribed by the researcher, and the notes were compared with the transcribed data in order to confirm consistency or contradictions.

\section{Data Analysis}

Throughout the data analysis, close attention to teachers' own stories was highlighted and thus, their stories were used as a main source of data. To identify and analyze the themes within individual as well as across the five participating teachers' stories and their own sense makings of the factors that contribute to ELs' struggles in their schools, ongoing open coding strategy of grounded theory (Strauss \& Corbin, 1998) was adopted. The researcher looked for any consistency or inconsistency in the participants' stories. 
Following the scholarship of the second-wave White teacher identity literature that it is crucially important to recognize the White privilege already in place in larger structures of society and schools at the same time understanding White teacher identity as multidimensional and complex, in this study, teachers' perpsectives on the contributing factors to ELs' struggles were viewed in part as a reproduction of White privilege but also as a possible site in which changes in the existing injustices for ELs can be imagined. In line with this thinking, the discussions of the findings below are organized into two broad themes-(1) teachers' perspectives that reflect race evasive perspectives, and (2) teachers' perspectives that reflect race conscious perspectives.

Inevitably, the researcher's particular perspectives and views influenced the data analysis which in turn influenced what was seen and not seen in terms of data categories. The discussion of own reaction to the participating teachers' responses are included at the end of the findings section. Also, the responses to the interviews pertain to the participating teachers' own perspectives, and therefore, the responses cannot be generalized. However, the findings from this study do illuminate the importance of attending to the complexity of White teachers' beliefs and perspectives about ELs academic challenges and what that means for more equitable educational opportunities for ELs.

\section{FINDINGS}

Looking across the data, in each teacher's perspectives, there were many similar dynamics of importance for this study in each teachers' perspectives. The data showed contradictions and tensions across teachers' perspectives but also within each individual teacher's perspectives. Therefore, teachers' beliefs revealed that their perspectives about the factors that contribute to ELs' academic challenges cannot be simplified only to race-evasive and color-blind since there were many incidences where teachers' beliefs reflected race-consciousness. Thus, the findings reported here illuminate the general, yet important to acknowledge, the complexity of teachers' race identity and thus their beliefs, and how they can impact their pedagogical actions and decisions that influence ELs' academic growth especially given that this study predicated in previous research findings that English language teaching is not racially neutral and there is inseparability of Whiteness and ESL teaching and learning (Kubota \& Lin; Motha, 2006).

Race Evasive Perspectives

The issues with using students' home language. All participating teachers stated that one of the main factors that contribute to ELs' struggles is the extensive use of students' home language at school and home. All five teachers believe that the frequent use of the home language delays the learning of English, the fluency in which they view as essential for ELs to succeed in their schools (Shim, 2014). All five teachers displayed the evidence of epistemological racism (Kubota, 2002; Kubota \& Lin, 2006), practices that perpetuate the hegemony of Whiteness in which English is the only legitimate ways of knowing and learning. Linda stated:

I think that the biggest problem for ELs is their parents letting them speak Spanish at home all the time. The kids need to speak English and I focus on grammar with my ELs because that's what they need. I know it is the easy thing to do, and the nice thing to go "Oh, it's okay at home." But, how is talking to the kids in Spanish helping them? Unless your kids are having a meltdown, their parents need to at least try to speak English to them. I think that is the biggest obstacle because, without having these kids learn English, they cannot learn in school (Shim, 2014).

This teacher identifies ELs' parents and ELs' continual usage of Spanish in their homes as the biggest problem. In other words, this teacher does not take into a consideration the possibility that ELs' parents may not speak English, and more importantly, cannot to recognize the value of maintaining ELs' first language in their second language learning (e.g., Cummins, 2000). Such perspectives reflect the characteristics of White privilege in which these teachers are reproducing the larger structural racial and linguistic hierarchy where English is privileged and seen as academically valuable. Mary similarly noted:

The parents, teachers, and ELs must realize the importance of being competent in English and not use so much Spanish. Otherwise, the students will be missing out on all sorts of opportunities. When you go to university, they are not going to translate for you. It's not like "Oh, I am sorry you don't speak English, and here is a Spanish version of biology. We will cater for all your needs." That's just not going to happen. If you work at McDonalds, the customers are not going to speak Spanish to you. You know, if I was French, I am not going to order the La Big Mac. I am going to order the Big Mac and if you don't know what that is, that's tough. Thinking that you can speak your home language in a different country is what's stunting their growth all around (Shim \& Bentahar, 2016).

Reflecting the construct of epistemological racism, this teacher argues students must speak only English to be successful in American society, thus seeing English as the only legitimate knowledge/language. Mary does not consider a multilingual society where many different languages are used and valued. Karen also stated:

I respect my students' home language, and I think it is great that their parents speak Spanish to them at home. I am all about that. However, I believe that the students who are not proficient in English should not be speaking Spanish at school. The reason is not because I don't respect students' home language but I think using Spanish delays the learning of English, and students are even more confused in learning a new language. To help my students, I usually throw a pizza party for them on Fridays if they spoke no Spanish during class on a given week.

David similarly noted:

In my teaching, I do not usually make reference to the home language of the ELs I have in class, and I also do not allow my students to speak in their home language in class. I offer practical advice to the ELs who wish to maintain 
their home language, but allowing students to speak in their home language at school does not help the students learn English (Shim, 2014)

The two high school teachers quoted above expressed their agreement about the importance of respecting students' home language. However, they both expressed that the use of students' home language hinders the learning of a second language and therefore, English should be the only means for learning in schools. Both of these teachers' viewpoints reflect that their perspectives directly influence their classroom management strategies, impacting what they do or do not do in class. For example, Karen celebrates with students when they do not speak Spanish in class by having a pizza party. On the other hand, not having a pizza party could easily be perceived by students as punishment for speaking their home language in class (Shim, 2014).

The teachers' attitudes discussed show that the use of students' home language is considered as an onstable to students' learning and to their learning English in particular which again confirms their embodiment of epistemological racism. However, research evidences that that ELs being able to think and utilize their first language produces a positive effect on individual learning (De Angelis \& Dewaele, 2009). In summary, the participating teachers view ELs' incompetency in English as the major limiting factor in their academic achievement, which aligns with the description of epistemological racism in which White privilege is inherently intertwined with what counts as academically valuable and rigorous (Kubota, 2002; Kubota \& Lin, 2006). In other words, English has been and continues to be a lingua franca in the world, and these teachers believe the competency in English is the deciding factor in becoming successful in school. What must be highlighted here is that there is not a single empirical evidence showing that forcing ELs to use only English while banning their first language is conducive in any way for ELs' social, emotional, and academic success.

EL Parents' Value for Education. Teachers also commented that another factory that contributes to ELs' struggles is that their parents do not value in their children's education Linda stated:

I ask myself, "Do the parents value education or not?" I think in the back of their minds, they are thinking that they are eventually going back to their country and so they think "why waste our time?" When parents do not value education, how can you expect their children to value education?

Nancy also noted:

EL students are very bright and their parents are also very intelligent. I mean, what the parents do is a sign of intelligence - just to pick up their things and move to another country for a betterment of their lives. I don't think I can just do that. The problem is the parents don't believe in themselves and in their children that they can be successful.

David noted likewise:

Students can't learn when they are not in class, and many ELLs often miss class. I don't think parents see how crucial coming to school is. They just let their children stay home. Without parents' support and beliefs that education is important, their children cannot succeed in school (Shim, 2014).

Again, the teachers see individual parents' and students' attitudes towards education as the main factor contributing to ELs' struggles in their schools. However, the participating teachers' assumption about EL parents' inability to recognize the value of education is supported by any evidence, therefore, their assumption is a mere speculation. No teacher was actually able to state that EL parents indicated to the teachers that they do not value their children's education. Displaying the epistemological racism, these teachers are making assumption about EL parents' dedication to their children's education equating the non-native speakers of English as less invested in Education while accepting the conditions of school as neutral. Thus, the participating teachers are not questioning the structures of school as a possible reason for ELs' struggles in schools. Instead, the teachers are pointing the problems to EL parents.

\section{Race Conscious Perspectives}

Thus far as shown above, the participating teachers' perspectives and attitudes reflect their race-evasive identity that is rooted in White privilege. In this section, however, I turn to the teachers' views that are inconsistent and contradictory from the ones shown above. For second-wave scholarship of White teacher identity, White teachers' identity just like those of everyone else's is constituted in and through multiple and often intense entanglements within various social structures (Jupp et al., 2016; Jupp \& Lensmire, 2016; Lensmire, 2011, 2014). Such premise explains why some inconsistencies and contradictions within and across the participating teachers arose. Put differently, while teachers' perspectives shown above stem more from the race evasive identity, those presented below seem to stem more from race conscious identity which demonstrate that these teachers identities are not stable and monolithic, instead they are constituted in and through different life experiences and thus their identities and attitudes are in the process of becoming. In other words, each individual teacher's perspectives are inevitably linked her/his socialization histories which are embodied within their identities. Hence, the fact that the teachers' comments are inconsistent and contradictory is not surprising since the social contexts and teachers' experiences that shape each teacher's racial identity may coalesce but also collide.

Misalignment between students' and school cultures. Teachers commented in their interviews that, in their view, the issue of mismatch between ELs' home cultures and the culture of schools is a factor contributing to ELs' struggles. Linda stated:

Have you even been invited to a Thanksgiving dinner to a family who's from a different culture? You know how awkward that experience is even if they are from the US and they all speak English. I experienced this when I was in 
college. Even if you know how to use their utensils and stuff, being in a place where the culture you are used to isn't the same as theirs is simply very uncomfortable. I think this is how the ELLs in my school feel every day (Shim, 2014).

Here, Linda is drawing on her personal experience during her college to imagine the difficulty of cultural gap ELs must be facing. Karen commented in a similar manner:

I think the way the school here is set up is very foreign to ELs. There are White students who know what to do, but most ELs have no idea, and schools can be a horror experience for them. ELs might feel that the school here isn't meant for them. Some people say that ELs should participate in more extracurricular activities, but if I feel I am an outsider in my class and when I am barely getting by, why would I want to join a basketball team? I think schools have unreasonable expectations for them, and the goal should be to re-think about what we are doing, so that the students are more comfortable (Shim, 2014).

Karen is drawing her own schooling experience as a teacher. Recall that these are the same teachers who previously expressed they believe that ELs should not speak their home language in class and that allowing the students to speak their home language at home and school can limit ELs learning. Nevertheless, here, those same teachers stated that they perceive a misalignment or mismatch between the school and students' cultures is a difficulty for ELs. These teachers are locating the reasons for ELs struggles in their schools outside of ELs and their parents' responsibility and their lack of ability. Hence, these teachers' points of views are vastly different from their earlier race evasive stance. Rather, the focus is on school and teachers, emphasizing the necessity of reflecting on how and why school is or is not accommodating ELs which shows these teachers' race conscious stances.

Unqualified teachers. The participating teachers also felt unqualified teachers are another factor adversely affecting ELs' school experiences. Nancy commented:

We have too few teachers who know what to do with ELLs. When I was going through my ESL certificate program, I learned how a very few teacher education programs actually prepare their pre-service teachers to work with ELLs, and most, if not all, teachers I work with in this schools have no idea how to help ELs.

David also expressed:

One of the problems I see is that we don't have enough qualified teachers who can assist ELs. Most teachers have no clue about what it's like to be in a new country and not being able to speak the host language. We need more professional developments for all teachers (Shim, 2014).

Recall again that these are the teachers who believe the problems associated with ELs' struggles in their schools located mostly in their use of their first language and their parents' not valuing their children's education. However, consistent with the teachers' race conscious perspectives discussed in the section immediately above, these teachers are now locating the issue with school structure and considering teachers are a part of school structure. They are not locating the reasons for ELs' struggles in students and their parents. Recognizing what contribute to individual racial identities are not easy to trace back directly and exactly, it appears that the race conscious identities that these teachers are speaking from in this section are acquired from their social experiences such as their experiences in their college as well as their later experiences as teachers in schools and education system.

\section{My Own Response to Teachers' Responses}

Recognizing the centrality of race in conducting our ESL/EFL research (Lee \& Simon-Maeda, 2006), included in this findings section is my own response to the participants' perspectives. I learned that engaging in this research project with White monolingual teachers of ELs is as much about the participants' reflecting on their perspectives and becoming as it is about the my own learning and becoming. Going into this project, my primary focus was on documenting and describing the evidences that show the participant' reinforcement of Whiteness in their everyday work of working with ELs, and my initial analyses were guided by such focus. Informed by the conceptual framework of the study, as I began paying much closer attention to the participants' experiences and stories, I also began to see how I too conceptualized my participants as deficient rather than active participants. I found myself wanting to intervene and correct the responses of participants during the interviews. However, I also realized that my attempt to change the participants' thinking was creating tension and resistance on the part of the participants and I should no longer assume that my knowledge and relationship with the participants was accurate. In other words, I needed to adopt the role of an unknowing researcher and pay closer attention to and value the participants' own accounts about their experiences and perspectives. Clearly, doing so was not without a challenge, and I believe that my struggle was due to two major reason. First, my internalized institutionalized knowledge restricted my focus on White teachers' race-evasive identities, whereby I saw them as subjects lacking race awareness (Jupp et al., 2016). Second, psychoanalytically speaking (Britzman, 2011), as a female teacher educator of Color, I have experienced gender and racial oppression throughout my life. Hence, I had to work against my own feelings of deficiency in order to overcome the tendency to project such feelings on the participants. Indeed, it took conscious and continuous efforts throughout the project to highlight (as oppose to undermine) participants' race conscious perspectives. I began to realize that what I initially saw as the participants' race-evasive reactions and contradictory statements are a very important part of their racial identities as they are grappling to come to grips with their own understandings of language issues that are inherently intertwined with their racial identities; therefore, they must not be dismissed solely as race evasive and color blind. 
The inability of most US schools and other places in the world to meet the academic needs of ELs is a major concern (Smith, Coggins, \& Cardosi, 2008), and more equitable educational opportunities for ELs are indeed a necessity. Based on previous research findings, this study assumed that race, racialization, and racism are major factors that shape language teaching and learning (Kubota \& Lin, 2006; Motha; 2006). For second-wave White teacher identity scholars, when a goal is to move the discuss of race and racism forward toward more equitable pedagogical practices and actions, one must understand the complexities of the identities of White teachers who make up the majority of teaching force (Jupp et al., 2016; Jupp \& Lensmire, 2016). The findings revealed several incidences in which the participants enacted Whiteness while also actively constructing knowledge about race conscious perspectives.

Second-wave White teacher identity studies call for the importance of acknowledging the larger structural inequality in place, the teachers' insistence on their students using only English in class and assuming that their viewpoints benefits ELs is not surprising, given that an English-only policy has historically dominated the educational policy in the United States (Crawford, 1992). Thus, such ideology is most likely a durable part of individual teacher's epistemological racism (Kubota, 2002; Kubota \& Lin, 2006). However, educators must remember that according to empirical evidence, the approach in which English-only is imposed contributes adversely to ELs' academic, social, and emotional growth, even when these teachers have good intention (Cummins, 2000). At the same time, these same teachers who acknowledged the misalignment between school and students' culture as a problem felt that the school and teachers should find ways to better accommodate ELs, which for many scholars in the field of education is a better way to support students' academic success and to work against inequality (Gonzales, Moll \& Amanti, 2005). Considering the demonstrated inconsistencies and contradictories in the participating teachers' perspectives teachers in this study, there are a few important implications drawn with respect to better meeting the needs of ELs in their school experiences. The implications presented here are general and suggestive, rather than confirmatory.

First, confirming the existing studies and the conceptual framework of this study, the participating teachers' perspectives revealed in this study are not autonomous but a reflective of the larger social structures and conditions in which their racial identities are formed. Such finding also shows why it is very difficult to dislodge the racial beliefs that are deeply internalized by individuals. As demonstrated in the teachers' comments in this study, the dispositions within individual's race evasive identities are pervasive, and these forces spoke durably and powerfully through each individual. Though not explicitly evidenced, the teachers' judgments against ELs' English proficiency levels and the legitimization of their perspectives will almost certainly impact their teaching, which shows how a dimension reinforcement of White privilege gets reproduced in local contexts regardless of an individual teacher's otherwise intention (Shim, 2014). In other words, while these teachers are not unsupportive of ELs' learning, but because the internalized and often unrecognized dispositions within their White race evasive identities, their race evasive perspectives present themselves as social reality (Omi \& Winant, 1994). Such findings also echoed the previous researching findings that English language teaching and learning are inevitably racialized and cannot be viewed as neutral (Taylor, 2006). Thus, teachers who are committed to ELs' academic success should recognize that the enduring dispositions in their racial identities may hiner what teachers do to actually support ELs' success in schools. Also, although individual change is possible, working against one's socialization histories to actually change one's perspectives and attitudes should not be viewed as a simple and one-time process.

Second, teachers' responses not only reflected their race evasive identities but also race conscious identities that are not entirely determined by the social structure under which it was initially formed. More specifically, the contradictions in the teachers' responses in this study reflect how the experiences such as in their college years or in the work environment that these teachers encountered later in life can create a space of change in their thinking. In such a potential space of change, the teachers' race evasive identities that usually incline them to unquestionably take the current school structure as natural, and thus blame ELs and their parents for their low academic achievement, may be altered. Here, Ladson-Billings' (2006) assertion that "the problem teachers confront is believing that successful teaching" is primarily about "what to do" when in actuality "the problem is rooted in how we think about the social context, about the students, about the curriculum and about instruction" (p. 30) seems to resonate powerfully in considering the necessity of recognizing then shifting teachers' perspectives that may be counterproductive to ELs' school experiences. Hence, while acknowledging that teachers are always situated within social structures such that no theory can extract individuals from those conditions of possibility and that "no theory is capable of showing all the underlying reasons for our thinking," (Shim, 2014) it is necessary to recognize teachers' race evasive identities that may alienate ELs while also attending to the teachers' race conscious identities that question the perspectives that are rooted in the larger structurings of inequality and inequity. In this regard, the incidences of contradictions within and across each teacher's beliefs must not be taken for granted but must be attended to as an extremely important locus of individual, institutional, and social change - these incidences of contradiction within and across teachers are where race evasive and race conscious identities co-exist. Hence, attending to teachers' stories imperative because doing so can reveal the complexities of their race identities as it did in this study.

What surfaced from the findings thus far is also a practical implication since that the experiences that teachers' encounter do have an impact on how they think about their EL students. Offering frequent training programs that help inform the teachers about the value of ELs' first language and why its continued use is an asset for ELs, particularly for the achievement of long-term academic and emotional benefits, may alter teachers' race-evasive perspectives (Shim, 
2014). Furthermore, such initiative would encourage teachers to reflect and reevaluate their perspectives, which, in turn, may shift their pedagogical practices for ELs in more productive ways. Teachers would also benefit from various training on how to students who speak more than one language more productively. The findings reported in this study demonstrate that most teachers share the view that students' first language background should be banned in classrooms and if possible, at homes. However, if the teachers were more knowledgeable about what research shows about working with multilingual students, they would likely be less inclined to prohibit the use of ELs' first language in classes and schools.

Many research studies have been focusing on how White teachers unintentionally perpetuate the system of domination in their teaching practices (Shim, 2014). Substantial attention has also been devoted to the question of how teachers of color can contribute to more equitable educational practices in working with students from various racial and linguistic backgrounds (Foley, Levinson, and Hurtig, 2000-2001). While recognizing that no teacher can escape our social and historical backgrounds, by utilizing second wave White teacher identity scholarship, this study attempted to show how White American monolingual ESL teachers can increase their capacities and capabilities by potentially changing their beliefs that can contribute significantly in ELs academic achievement. Recalling the significant gap between the English-speaking White teacher population and the EL student population in the US as well as other nations in the world, as well as the achievement gap between ELs and non-ELLs, the findings of this study add yet another angle from which to understand the challenges ELs face in school and how teachers' assumptions may inhibit or contribute to ELs' learnings (Shim, 2014).

\section{REFERENCES}

[1] Assaf, L. C., Garza. R., \& Batt, J. (2010). Multicultural Teacher Education: Examining the Perceptions, Practices, and Coherence in One Teacher Preparation Program. Teacher Education Quarterly, 37(2), 115-135.

[2] Bergh, L., Denessen, E., Hornstra, L., Voeten, M., \& Holland, R. W. (2010). The implicit prejudiced attitudes of teachers: Relations to teacher expectations and the ethnic achievement gap. American Educational Research Journal, 47(2), $497-527$.

[3] Britzman, D. P. (2011). Freud and education. New York, NY: Routledge.

[4] Crawford, J. (1992). Hold your tongue: Bilingualism and the politics of "English Only." New York, NY: Addison-Wesley Publishing Company.

[5] Cummins, J. (2000). Language, power and pedagogy: Bilingual children in the crossfire. Clevedon, UK: Multilingual Matters.

[6] De Angelis, G., \& Dewaele, J. M. (2009). The development of psycholinguistic research on crosslinguistic influence. In L. Aronin, \& B. Hufeisen (Eds.), The exploration of multilingualism (pp. 63-77). Amsterdam, Netherlands: John Benjamins.

[7] Doorn, K. \& Schumm, J. S. (2013). Attitudes of pre-service teachers regarding linguistic diversity in the general education classroom. Journal of Reading Education, 38(3), 28-37.

[8] Flores, N. \& Rosa, J. (2015). Undoing appropriateness: Raciolinguistic ideologies and language diversity in education. Harvard Educational Review, 85(2), 149-171.

[9] Foley, D., Levinson, B., \& Hurtig, J. (2000-2001). Anthropology goes inside: The new educational ethnography of ethnicity and gender. Review of Research in Education, 25 (2000-2001), 37-98.

[10] Gay, G. (2010). Acting on beliefs in teacher education for cultural diversity. Journal of Teacher Education, 61(1-2), 143-152.

[11] Gay, K., \& Kirkland, K. (2003). Developing cultural critical consciousness and self-reflection in pre-service teacher education. Theory into Practice, 42(3), 181-187.

[12] Gonzales, N., Moll, L., \& Amanti, C. (2005). Funds of knowledge: Theorizing practices in household, communities, and classrooms. Mahwah, NJ: Lawrence Erlbaum Association, Inc., Publishers.

[13] Jupp, J., Berry, T. R., \& Lensmire, T. J. (2016). Second-wave White teacher identity studies: A review of White teacher identity literatures from 2004 through 2014. Review of Educational Research, 86(4), 1151-1191.

[14] Jupp, J., \& Lensmire, T. J. (2016). Second-wave White teacher identity studies: toward complexity and reflexivity in the racial conscientization of white teachers. International Journal of Qualitative Studies in Education, 29(8), 985-988.

[15] Jupp, J., \& Slattery, P. (2010). Committed White male teachers and identifications: Toward creative identifications and a "Second Wave" of White identity studies. Curriculum Inquiry, 40(3), 454-474.

[16] Kang, H., \& Veitch. (2017). Mainstream Teacher Candidates' perspectives on ESL writing: The effects of writing identity and rater background. TESOL Quarterly, 51(2), 249-274.

[17] Kubota, R. (2002). The author responds. Un(ravelling) racism in a nice field like TESOL. TESOL Quarterly, 36(1), 84-92.

[18] Kubota, R \& Lin, A. (2006). Race and TESOL: Introduction to concepts and theories. TESOL Quarterly, 40(3), $471-494$.

[19] Kumaravadivelu, B. (2003). A postmethod perspective on English language teaching. World Englishes, 22 , $539-550$.

[20] Ladson-Billings, G. (2006). "Yes, but how do we do it? Practicing culturally relevant pedagogy. In J. Landsman \& C. W. Lewis (Eds.), White teachers/diverse classrooms (pp. 29-42). Sterling, VA: Stylus.

[21] Lee, E \& Simon-Maeda, A. (2006). Racialized research in identities in ESL/EFL research. TESOL Quarterly, 40(3), 573-594.

[22] Lensmire, T. J. (2011). Laughing White men. Journal of Curriculum Theorizing, 27(3), 102-116.

[23] Lensmire, T. J. (2014). White men's racial Others. Teachers College Record, 116, 1-32.

[24] Lensmire, T. J., McManimon, S. K., Tierney, J. D., Lee-Nichols M. E., Casey, Z. A., Lensmire, A., \& Davis, B. M. (2013). McIntosh as synecdoche: How teacher education's focus on White privilege undermines antiracism. Harvard Educational Review, 83(3), 410-431.

[25] Leonardo, Z. (2005). Through the Multicultural Glass: Althusser, ideology and race relations in post-civil rights America. Policy Futures in Education, 3(4), 400-412.

[26] Lowenstein, K. L. (2009). The work of multicultural teacher education: Reconceptualizing White teacher candidates as learners. Review of Educational Research, 79(1), 163-196. 
[27] Macnab, D. S., \& Payne, F. (2003). Beliefs, attitudes and practices in mathematics teaching: Perceptions of Scottish primary school student teachers. Journal of Education for Teaching, 29, 55-65.

[28] McIntyre, A. (1997). Constructing an image of a White teacher. Teachers College Record, 98(4), 653-681.

[29] McIntyre, A. (2002). Exploring Whiteness and multicultural education with prospective teachers. Curriculum Inquiry, 32(1), 31-49.

[30] Milner, H. R. (2003). Teacher reflection and race in cultural contexts: History, meaning, and methods in teaching. Theory into Practice, 42(3), 173-180.

[31] Motha, S. (2006). Racializing ESOL teacher identities in the U.S. K-12 public schools. TESOL Quarterly, 40(3), $495-518$.

[32] Omi, M., \&Winant, H. (1994). Racial formation in the United States: From the 1960s to the 1990s. New York, NY: Routledge.

[33] O’Neal, D. D., Ringler, M., \& Rodriguez, D. (2008). Teachers' perceptions of their preparation for teaching linguistically and culturally diverse learners in rural eastern North Carolina. The Rural Educator, 30(1), 5-13.

[34] Pennycook, A. (2001). Critical applied linguistics. Mahwah, NJ: Lawrence Erlbaum.

[35] Peregoy, S. F., \& Boyle, O. F. (1997). Reading, writing, and learning in ESL (2nd ed.). New York, NY: Longman.

[36] Pettit, S. K. (2011). Teachers' beliefs about English language learners in the mainstream classroom: A review of the literature. International Multilingual Research Journal, 5, 123-147.

[37] Picower, B. (2009). The unexamined Whiteness of teaching: how White teachers maintain and enact dominant racial ideologies. Race, Ethnicity and Education, 12(2), 197-215.

[38] Rhedding-Jones, J. (2002). English elsewhere: Glocalization, assessment and ethics. Journal of Curriculum Studies, 34(4), 383-404.

[39] Reed, K. (2010). Multicultural education for rural schools: Creating relevancy in rural America. The Rural Educator, 31(2), 1520.

[40] Rueda, R., \& Garcia, E. (1994). Teachers' beliefs about reading assessment with Latino language minority students. Washington, DC: Office of Educational and Improvement. (ERIC Document Reproduction Service No. ED376721).

[41] Sheng, Z., Sheng, S., \& Anderson, C. J. (2011). Dropping out of school among ELL students: Implications to schools and teacher education. The Clearing House, 84(98), 98-103.

[42] Shim, J. M. (2018). Co-existence of race-visible and race-evasive identifications: Complexifying one white male teacher's racial knowledge. Teaching and Teacher Education, 70 (February), 132-141.

[43] Shim, J. M. (2014). A Bourdieuian analysis: Teachers' beliefs about English language learners' academic challenges. International Journal of Multicultural Education, 16(1), 40-55.

[44] Shim, J. M. \& Bentahar, A. (2016). Practicing collaborative relations of power: English language learners' perspectives. The Journal of Language Teaching and Learning, 6(1), 66-78.

[45] Shim, J. M. \& Shur, A. M. (2018). Learning from ELLs' perspectives: Mismatch between ELL and teacher perspectives on ELL learning experiences. English Language Teaching, 11(1). doi: 10.5539/elt.v11n1p21.

[46] Smith, J. M., Coggins, C., \& Cardosi, J. M. (2008). Best practices for English language learners in Massachusetts: Five years after the Question 2 mandate. Equity \& Excellence in Education, 41(3), 293-310.

[47] Shim, J. M. (2014). Bilingual speakers of English and Korean and code switching practice. International Journal of Education, $6(1), 21-48$

[48] Sleeter, C. (1992). Resisting racial awareness: How teachers understand the social order from their racial, gender, and class locations. Educational Foundations, 6(2), 7-31.

[49] Sleeter, C. E. (1993). How White teachers construct race. In C. McCarthy \& W. Crichlow (Eds.), Race, identity, and representation in education (pp. 157-171). New York, NY: Routledge.

[50] Sleeter, C. (2002). Advancing a White discourse: A response to Scheurich. In J. Scheurich (Ed.), Anti-racist scholarship: An advocacy (pp. 42-45). New York, NY: State University of New York Press.

[51] Strauss, A., \& Corbin, J. (1998). Basics of qualitative research: Techniques and procedures for developing grounded theory. Thousand Oaks, CA: Sage.

[52] Taylor, L. (2006). Wrestling with race: the implications of integrative antiracism education for immigrant ESL youth. Tesol Quarterly, 40(3), 519-544.

[53] United States Census Bureau. (2000). “American Fact Finder [Tables and Charts]." http://factfinder.census.gov/servlet/BasicFactsServlet. Retrieved on January 7, 2018.

[54] Walker-Dalhouse, D., Sanders, V., \& Dalhouse, A. D. (2009). A university and middle-school partnership: Preservice teachers' attitudes toward ELL students. Literacy Research and Instruction, 48(4), 337-349.

[55] Wyoming Department of Education. (2017). Statewide English Language Learner Summary. Retrieved from https://portals.edu.wyoming.gov/Reports/Public/wde-reports-2012/public-reports/stat2/statewideenglishlanguagelearnersummary. Retrieved on March 3, 2018.

[56] Zumwalt, K., \& Craig, E. (2005). Teachers' characteristics: Research on the demographic profile. In M. Cochran-Smith \& K. M. Zeichner (Eds.), Studying teacher education: The report of the AERA penal on research and teacher education (pp. 111156). Mahwah, NJ: Lawrence Erlbaum.

[57] Zhang, J \& Pelttari, C. (2013). Exploring the emotions and needs of English language learners: Facilicating pre-service and inservice teachers' recognition of the tasks facing language learners. Journal of Multilingual and Multicultural Development, $35(2), 179-194$.

Jenna Min Shim is an associate professor in the School of Teacher Education at the University of Wyoming. Her address is 209 McWhinnie Hall, 1000 E. University Ave., Laramie, WY 82071, USA. Her email address is jshim@ uwyo.edu. Her primary research interests center on anti-racist pedagogies and teacher education for English learners with the specific goal of contributing to social change in favor of historically marginalized groups. Her work has been published in Curriculum Inquiry, Journal of Curriculum 
Studies, Teaching and Teacher Education, Teaching Education, Journal of Philosophy of Education, and Journal of Curriculum Theorizing and Intercultural Education. 